\title{
Correlation of fasting blood sugar at the time of penile prosthesis surgery with the level of glycated hemoglobin and the outcome of surgery
}

Mohamad Haobus ${ }^{1}$, Raed Almannie ${ }^{2}$, Mohammed Aziz $^{3}$, Mohammed Farag $^{4}$, David Ralph ${ }^{5}$, John Mulhall ${ }^{6}$ and Saleh Binsaleh ${ }^{2 *}$ (1)

\begin{abstract}
Background: The role of glycemic control in predicting implant infection and other surgical complications is debatable. This study aimed to assess the potential correlation between fasting blood sugar (FBS) levels prior to penile prosthesis surgery (PPS) and the surgical outcomes.

Methods: A retrospective study from data collected prospectively in 2015 in a single center. Patients who underwent penile implant procedures were included. Exclusion criteria were if surgery done by low-volume implanter, patients who required revision surgery or not diagnosed with diabetes mellitus. Management was standardized to all patients.

Results: All complications whether minor or major were documented up to three years. One year after the surgery a Likert scale questionnaire was completed by the patients. In total, 218 patients completed the study at last follow-up. Complications rate was $6.25 \%$. The rate of infection requiring explantation was $3.8 \% .0 .9 \%$ of patients had a superficial infection managed successfully with conservative management. $0.9 \%$ had erosion and $0.9 \%$ had mechanical failure. There was no statistically significant difference in FBS or glycated hemoglobin ( $\mathrm{HbA1c}$ ) levels in patients with postoperative complications compared to patients with satisfactory postoperative course. FBS level on the day of surgery was within $20 \mathrm{mg} / \mathrm{dL}(1.11 \mathrm{mmol} / \mathrm{L})$ of the expected range based on $\mathrm{HbA1c}$ measurement in 62 patients (28.44\%), while in 146 patients (66.98\%) the FBS was not within $20 \mathrm{mg} / \mathrm{dl}(1.11 \mathrm{mmol} / \mathrm{L})$ of the expected range based on preoperative HbA1c level.
\end{abstract}

Conclusion: FBS levels on the day of surgery are not correlated with HbA1c levels and PPS outcomes.

\section{Background}

Diabetes mellitus (DM) is reaching a pandemic level worldwide, with increasing incidence of young onset type 2 diabetes $[1,2]$. The association between DM and the development of erectile dysfunction (ED) has been described more than 200 years ago [3], and the prevalence of ED in diabetic men is $\geq 50 \%$.

\footnotetext{
*Correspondence: surgon@hotmail.com

2 Division of Urology, Department of Surgery, Faculty of Medicine, King

Saud University, Riyadh, Saudi Arabia

Full list of author information is available at the end of the article
}

The pathophysiology of diabetes-induced ED is multifactorial, and the proposed mechanisms include: elevated advanced glycation end-products, increased levels of oxygen free radicals, impaired nitric oxide synthesis, increased endothelin B receptor binding sites and upregulated Ras homolog family member A (RhoA/Rhokinase pathway), neuropathic damage and impaired cyclic guanosine monophosphate (cGMP)-dependent protein kinase-1 [4].

Diabetics men often present with severe ED that is more difficult to treat medically compared with 
non-diabetic men [1]. The likelihood of undergoing penile implant is doubled in diabetic men having ED compared to non-diabetics [5]. In the Prospective Registry of Outcomes with Penile Prosthesis for Erectile Restoration (PROPPER) study, the authors found that $>20 \%$ of men undergoing penile prosthesis surgery were diabetics [6].

Infection remains one of the most devastating complications in penile prosthesis surgery. Large variations in the reported infection rates exist, but in most studies the rate is between 1 and $4 \%$. The incidence of infection reaches $13 \%$ for re-implant procedures and up to $21.7 \%$ if penile reconstruction was done [6-8].

The role of glycemic control in predicting implant infection is debatable. Some authors believe that diabetes itself is a risk factor for penile implant infection and the risk increases with uncontrolled blood sugar [9-13]. Other authors oppose any association between DM and rate of infections, and they do not recommend glycemic control as a predictor for penile implant infection [14-16]. In a large multicenter prospective study of more than 900 implants by our group, it was found that uncontrolled DM is associated with an increased risk of infection after penile prosthesis surgery. Others also showed that the risk is directly related to glycated hemoglobin (HbA1c) level [16, 17].

DM is a heterogeneous disease in its severity: While some patients are well controlled and do not have significant end-organ damage, others have severe manifestations, e.g., ED, cardiovascular disease, nephropathy, retinopathy and neuropathy. $\mathrm{HbA1c}$ is the test that most closely measures how well diabetes is controlled [16]. Many papers were published investigating the correlation between DM and risk of penile implant infection but most of them compared diabetics with non-diabetics $[6,9,11,12,15]$. Few available data compared controlled diabetics with non-controlled using $\mathrm{HbA1c}[8,13,16]$ and only one recent paper investigated blood glucose level before surgery [18].

Our aim in this study is to investigate the relation between fasting blood sugar (FBS) at the time of penile implant and the surgical outcome (complications and patient satisfaction).

\section{Methods}

\subsection{Study design}

This study is based on a prospectively built large database.

\subsection{Study sitting and study participants}

After approval of our local institutional ethics committee, we analyzed the data of penile implant procedures in one full year (2015) in one high-volume facility specialized in andrological surgery. The data collected for each procedure include: surgeon, patient demographics, indication for surgery, procedure-related data (preoperative, intraoperative and postoperative notes) and complications. Peyronie's disease (PD) was diagnosed primarily clinically by identifying penile plaque and/or deformity during examination. Then this was confirmed with Duplex ultrasonography.

\subsection{Inclusion criteria}

Diabetic patients who underwent penile implant surgery in 2015 were included in this study.

\subsection{Exclusion criteria}

Non-diabetic men, revision surgery, if extra maneuvers are needed (e.g., grafting), if surgery was done by a lowvolume penile implantation surgeon. For the purpose of the study, a low-volume surgeon was defined as a surgeon who had performed $<12$ penile implant procedures in the study period.

\subsection{Data collection}

The preoperative counseling focused on the goal of surgery, the choice of the device and a detailed explanation of the possible complications. All the complications explained were listed in the consent, which is signed by all patients. The preoperative preparation was standardized and includes: bathing nightly with antibacterial soap for three nights before surgery, avoid shaving which is done in the operating room, administration of $240 \mathrm{mg}$ intravenous gentamycin $2 \mathrm{~h}$ preoperatively and $1 \mathrm{~g}$ ceftriaxone was given before induction of anesthesia. HbA1c usually done one week before surgery. A blood sample to check fasting blood sugar was taken when patient admitted in the early morning the day of surgery.

All procedures in this study were done under spinal anesthesia. Shaving was done by razor and the prepping was with chlorhexidine-alcohol. For inflatable implants (IPP), all procedures were done through penoscrotal approach. For malleable implants (MPP), the preferred approach was a ventral raphe incision. Postoperatively, patients were admitted for one day. After discharge the follow-up protocol was: twice a week for the first 2 weeks, weekly for weeks 3 and 4, and every 3 months for one year. Infection diagnosis was based on clinical judgment, and all infections were confirmed at the time of explant surgery using bacterial and fungal cultures.

Patient satisfaction was measured by a Likert scale question, which was done at 1-year follow-up. The patients were asked about the overall satisfaction. The answer was scored from 1 to 5 where 5 was very satisfied, 4 satisfied, 3 neutral, 2 dissatisfied and 1 very dissatisfied. 


\subsection{Data analysis}

Statistical analyses were conducted using STATA version 13 (StataCorp. 2013. Stata Statistical Software: Release 13. College Station, TX: StataCorp LP.). The t-test, MannWhitney U test, Pearson's Chi-square and Fisher's exact test were used as appropriate. Multivariate logistic regression was used to assess for independent predictors of infection.

\section{Results}

In total, 218 patients were included in this study. Eightyfive patients underwent IPP and 133 patients underwent MPP. For all MPP, the device was Genesis (Coloplast Corporation, Minneapolis, MN, USA). For IPP, 77 devices were Titan (Coloplast Corporation, Minneapolis, MN, USA), 4 were LGX and 4 were Ambicor (American Medical Systems, Minnetonka, MN, USA). The patient characteristics are summarized in Table 1.

Table 1 Patient characteristics

\begin{tabular}{lc}
\hline Data & Result \\
\hline Mean age (years) & 57.7 \\
Mean BMI (kg/m2) & 29.8 \\
Mean HbA1c (\%) & 7.9 \\
Expected FBS based on HbA1c (mg/dL) & 181 \\
Mean day of surgery FBS (mg/dL) & 154 \\
Patients with Peyronie's disease & $35 \%$ \\
Current smoker & $21 \%$ \\
Exsmoker & $7.6 \%$ \\
HTN & $38 \%$ \\
Ischemic heart disease & $10.5 \%$ \\
Malleable prosthesis & $61 \%$ \\
Inflatable prosthesis & $39 \%$ \\
\hline The data are expressed as mean, number and percent (\%), according to the \\
statistic used. BMI body mass index, HbA1c glycated hemoglobin, FBS fasting \\
blood sugar, HTN hypertension
\end{tabular}

The infection rate was $4.6 \%$ (10 infected implants that were all removed). Eight were MPP (6\% infection rate), and two were IPP (2.4\% infection rate). Both infected IPP were Coloplast Titan. Two patients had superficial wound infection $(0.9 \%)$ with successful conservative management (one IPP and one MPP). Two patients with Coloplast Titan OTR had pump failure (2\% of IPP cases) needed reoperation. Two patients had erosion, and one of them had associated infection. (Both were MPP.) Two patients had mechanical failure, and one of them was associated with infected hematoma. (Both were IPP.) There was no statistically significant difference in FBS in patients with unremarkable postoperative course $(152 \mathrm{mg} / \mathrm{dL}-8.4 \mathrm{mmol} / \mathrm{L}) \mathrm{com}$ pared to those who had major complications $(183 \mathrm{mg} /$ $\mathrm{dL}-10.17 \mathrm{mmol} / \mathrm{L}, P=0.07)$. Table 2 shows the list of major complications and their rate based on glycemic control, BMI, device type and the presence of Peyronie's disease.

The majority of patients were very satisfied or satisfied $(88 \%)$ (Table 3). Fourteen patients $(6.5 \%)$ were neutral; they were patients who had complications that were treated conservatively. The remaining patients (5.5\%) were dissatisfied or very dissatisfied; those were patients who had a major complication requiring removal of the implant.

\section{Discussion}

Penile prosthesis implantation is the gold standard treatment for patient's refractory to other less invasive therapy, such as phosphodiesterase type 5 (PDE-5). The rates of infection have decreased over the past decade, because of improvements in device technology like antibioticsand hydrophilic-coated implants. But infection is still the most feared complication. It often demands reoperation and can increase the cost of care as much as sixfold [19].

Diabetics are at high risk for infections, due to immune dysfunction, diabetic neuropathy and poor circulation.

Table 2 Rate of major complications based on glycemic control, BMI, device type and the presence of Peyronie's disease

\begin{tabular}{|c|c|c|c|c|c|}
\hline & $\begin{array}{l}\text { No complications } \\
(N=195)\end{array}$ & All infections $(N=12)$ & $\begin{array}{l}\text { Infection requiring } \\
\text { removal }(N=10)\end{array}$ & Erosion $(N=2)$ & $\begin{array}{l}\text { Pump } \\
\text { failure } \\
(N=2)\end{array}$ \\
\hline HbA1c (mean) (\%) & 7.9 & $8.6^{*}(p=0.06)$ & 7.7 & 7.9 & 7.3 \\
\hline FBS (mean) (mg/dL) & 152 & $183 *(p=0.07)$ & 176 & 200 & 133 \\
\hline BMI (mean) & 29.8 & $30.9 *(p=0.73)$ & 29.5 & 26.1 & 31 \\
\hline Inflatable prosthesis & $94 \%$ & $4.5 \%$ & $1.5 \%$ & $0 \%$ & $2 \%$ \\
\hline Malleable prosthesis & $92 \%$ & $4.9 \%$ & $4.9 \%$ & $1.4 \%$ & - \\
\hline Peyronie's & $36 \%$ & $18 \%$ & $25 \%$ & $0 \%$ & $0 \%$ \\
\hline
\end{tabular}

*versus patients without complications

$B M I$ body mass index, HbA1c glycated hemoglobin, FBS fasting blood sugar 
Table 3 Satisfaction scale

\begin{tabular}{lcll}
\hline Scale & Number & Mean HbA1c & FBS $(\mathbf{m g} / \mathbf{d L})$ \\
\hline 5 & 137 & 7.9 & 152 \\
4 & 55 & 7.9 & 155 \\
3 & 14 & 8 & 168 \\
2 & 4 & 7.7 & 151 \\
1 & 8 & 7.1 & 144 \\
\hline
\end{tabular}

HbA1c glycated hemoglobin, FBS fasting blood sugar

However, it remains unclear whether diabetes significantly increase rate of infection after penile prosthesis implantation. Lipsky et al studied DM as a potential risk factor for IPP infection, and the study included 14,969 patients who underwent initial IPP implantation from 1995 to 2014. About 30\% of the cohort were diabetic. The overall infection rate was $343 / 14,969$ (2.3\%). Infectious complications were experienced by $3 \%(133 / 4,478)$ of diabetic patients and $2 \%(210 / 10,491)$ of non-diabetic patients $(P<0.001)$. They concluded that DM is a risk factor for IPP infection. They also raised the question of whether this increased risk can be mitigated by optimization of glycemic control before surgery [20].

On the other hand, Osman et al. retrospectively analyzed 875 diabetic patients who underwent primary penile prosthesis implantation from 18 high-volume penile prosthesis implantation surgeons throughout the USA, Germany, Belgium and South Korea. Preoperative $\mathrm{HbA1c}$ and blood glucose levels within $6 \mathrm{~h}$ of surgery were assessed in univariate and multivariate models for correlation with postoperative infection, revision and explanation rates. They did not find any correlation between preoperative blood glucose levels or HbAlc levels and postoperative infection rates: $p=0.220$ and $p=0.598$, respectively. The same group on multivariate analysis found that a history of diabetes-related complication was a significant predictor of higher revision rates $(p=0.034)$, but was nonsignificant for infection or explantation rates [18].

In the present study, we analyzed the data of penile implant procedures in one full year (2015) in a highvolume center specialized in penile prosthesis surgery. Exclusion criteria included non-diabetics, revision surgery and procedures done by low-volume surgeons to minimize other predictors of postoperative complications. Preoperative, intraoperative and postoperative protocols (infection control protocols) were identical for all patients.

All minor (local edema, ecchymosis, pain) and major (infection, erosion, mechanical failure) complications as early as the 1st postoperative week and followed up to 3 years were recorded.
Our results showed that FBS level (on the day of surgery) does not correlate with the rate of complications when compared with patients with unremarkable postoperative course (see Table 2). Also, there was no correlation between FBS level with patient satisfaction (see Table 3).

Strengths of the present study include its relative unique nature because it was performed in a geographic location notorious for a high rate of DM in addition to other comorbidities like obesity and hypertension. All the procedures were standardized in terms of preoperative, operative and postoperative protocols in a high-volume center specialized for penile implants.

However, this study has some limitations: firstly the relatively low number of infected implants and the somewhat limited nature of the Likert scale used to assess patient satisfaction.

\section{Conclusions}

No correlation between day of surgery FBS and outcome (complications and patient satisfaction) of penile prosthesis surgery, or with $\mathrm{HbA1c}$ of same cohort of patients.

\section{Abbreviations}

FBS: Fasting blood sugar; PPS: Penile prosthesis surgery; HbA1c: Glycated hemoglobin; DM: Diabetes mellitus; ED: Erectile dysfunction; cGMP: Cyclic guanosine monophosphate; IPP: Inflatable penile implants; MPP: Malleable penile implants; PDE-5: Phosphodiesterase type 5.

\section{Acknowledgements}

Not applicable.

\section{Authors' contributions}

MH developed the concept note and the protocol. He did data collection and analysis. He did manuscript writing. RA did protocol development and manuscript writing. MA did protocol writing and manuscript writing. MF also did protocol development and manuscript writing. DR was involved in protocol development and manuscript writing. JM had contributed to protocol development and manuscript writing. SB took part in protocol development and manuscript writing. All authors read and approved the final manuscript.

\section{Funding}

This study has no funding.

Availability of data and materials

The datasets used and/or analyzed during the current study are available from the corresponding author on reasonable request.

\section{Declarations}

Ethics approval and consent to participate

This study was approved by Elaj Group Research Ethics Committee with Approval No. [3/2018 EG]. The study patients provided written consent.

\section{Consent for publication}

Not applicable.

Competing interests

The authors declare that they have no competing interests. 


\begin{abstract}
Author details
${ }^{1}$ Urology, Al-Themal Medical Center, Abha, Saudi Arabia. ${ }^{2}$ Division of Urology, Department of Surgery, Faculty of Medicine, King Saud University, Riyadh, Saudi Arabia. ${ }^{3}$ Faculty of Medicine, Urology, Menoufia University, Menoufia, Egypt. ${ }^{4}$ Urology Department, Faculty of Medicine, Al-Azhar University, Assiut, Egypt. ${ }^{5}$ St Peter's Andrology Centre and the Institute of Urology, UCLH, London, UK. ${ }^{6}$ Sexual and Reproductive Medicine Program, Memorial Sloan Kettering Cancer, New York, NY, USA.
\end{abstract}

Received: 13 January 2021 Accepted: 22 June 2021

Published online: 02 July 2021

\section{References}

1. Malavige LS, Levy JC (2009) Erectile dysfunction in diabetes mellitus. J Sex Med 6(5):1232-1247. https://doi.org/10.1111/j.1743-6109.2008.01168.x (Epub 2009 Feb 10)

2. McCulloch DK, Campbell IW, Wu FC, Prescott RJ, Clarke BF (1980) The prevalence of diabetic impotence. Diabetologia 18:279-283

3. Thorve VS, Kshirsagar AD, Vyawahare NS, Joshi VS, Ingale KG, Mohite RJ (2011) Diabetes-induced erectile dysfunction: epidemiology, pathophysiology and management. J Diabetes Complic 25:129-136

4. Walsh TJ, Hotaling JM, Smith A, Saigal C, Wessells H (2014) Men with diabetes may requiremore aggressive treatment for erectile dysfunction. Int J Impot Res 26:112-115

5. Henry GD, Karpman E, Brant W et al (2016) The who, how and what of real-world penileimplantation in 2015: the PROPPER registry baseline data. J Urol 195:427-433

6. Christodoulidou M, Pearce I (2016) Infection of penile prostheses in patients with diabetes mellitus. Surg Infect (Larchmt) 17:2-8

7. Habous M, Farag M, Williamson B, Laban O, Mahmoud S, Abdelwahab O, Elkhouly M, Kamil U, Binsaleh S, Tal R, Ralph D, Mulhall JP (2016) Conservative therapy is an effective option in patients with localized infection after penile implant surgery. J Sex Med 13(6):972-976. https://doi.org/10. 1016/j.jsxm.2016.04.064 (Epub 2016 May 6)

8. Bishop JR, Moul JW, Sihelnik SA, Peppas DS, Gormley TS, McLeod DG (1992) Use of glycosylated hemoglobin to identify diabetics at high risk for penile periprosthetic infections. J Urol 147:386-388

9. Levine LA, Becher EF, Bella AJ, Brant WO, Kohler TS, Martinez-Salamanca JI, Trost L, Morey AF (2016) Penile prosthesis surgery: current recommendations from the international consultation on sexual medicine. J Sex Med 13(4):489-518. https://doi.org/10.1016/j.jsxm.2016.01.017 (Epub 2016 Mar 25)
10. Li K, Brandes ER, Chang SL et al (2019) Trends in penile prosthesis implantation and analysis of predictive factors for removal. World J Urol 37(4):639-646. https://doi.org/10.1007/s00345-018-2491-4 (Epub 2018 Sep 24)

11. Mulcahy JJ, Carson CC 3rd (2011) Long-term infection rates in diabetic patients implanted with antibiotic-impregnated versus nonimpregnated inflatable penile prostheses: 7-year outcomes. Eur Urol 60:167-172

12. Carvajal A, Benavides J, García-Perdomo HA, Henry GD (2020) Risk factors associated with penile prosthesis infection: systematic review and meta-analysis. Int J Impot Res 32(6):587-597. https://doi.org/10.1038/ s41443-020-0232-x

13. Wilson SK, Carson CC, Cleves MA, Delk JR 2nd (1998) Quantifying risk of penile prosthesis infection with elevated glycosylated hemoglobin. J Urol 159:1537-1540

14. Mahon J, Dornbier R, Wegrzyn G, Faraday MM, Sadeghi-Nejad H, Hakim L, McVary KT (2019) Infectious adverse events following the placement of a penile prosthesis: a systematic review. Sex Med Rev. https://doi.org/10. 1016/j.sxmr.2019.07.005

15. Pineda M, Burnett AL (2016) Penile prosthesis infections-A review of risk factors, prevention, and treatment. Sex Med Rev 4(4):389-398. https://doi. org/10.1016/j.sxmr.2016.03.003 (Epub 2016 May 13)

16. Habous M, Tal R, Tealab A, Soliman T, Nassar M, Mekawi Z, Mahmoud S, Abdelwahab O, Elkhouly M, Kamr H, Remeah A, Binsaleh S, Ralph D, Mulhall J (2018) Defining a glycated haemoglobin (HbA1c) level that predicts increased risk of penile implant infection. BJU Int 121(2):293-300. https:// doi.org/10.1111/bju.14076 (Epub 2017 Dec 1)

17. Holland B, Kohler T (2015) Minimizing penile implant infection: a literature review of patient and surgical factors. Curr Urol Rep 16:81

18. Osman MM, Huynh LM, El-Khatib FM et al (2020) Immediate preoperative blood glucose and hemoglobin a1c levels are not predictive of postoperative infections in diabetic men undergoing penile prosthesis placement. Int J Impot Res. https://doi.org/10.1038/s41443-020-0261-5

19. Huynh LM, Osman MM, Yafi FA (2020) Risk profiling in patients undergoing penile prosthesis implantation. Asian J Androl 22(1):8-14

20. Lipsky MJ, Onyeji I, Golan R (2019) Diabetes is a risk factor for inflatable penile prosthesis infection: analysis of a large statewide database. Sex Med 7:35-40

\section{Publisher's Note}

Springer Nature remains neutral with regard to jurisdictional claims in published maps and institutional affiliations.

\section{Submit your manuscript to a SpringerOpen ${ }^{\circ}$ journal and benefit from:}

- Convenient online submission

- Rigorous peer review

- Open access: articles freely available online

- High visibility within the field

- Retaining the copyright to your article

Submit your next manuscript at springeropen.com 